\title{
Propriedades mecânicas e morfológicas de melão desidratado em diferentes pressões de trabalho.
}

\author{
Júlia D. Arid (IC), Flávio L. Schmidt (PQ), Hulda N. M. Chambi (PQ)
}

\section{Resumo}

Melão amarelo foi desidratado com suco concentrado de uva (SU) e solução de sacarose, sendo que a variação na pressão da desidratação osmótica não teve efeito significativo nas propriedades mecânicas e morfológicas do melão. Um produto mais firme e com baixa atividade de água foi obtido com SU.

Palavras Chave: Melão amarelo, propriedades mecânicas, morfologia.

\section{Introdução}

A desidratação osmótica (DO) é um processo utilizado para a remoção parcial de água dos alimentos e é baseada na diferença de concentração de solutos entre a fruta e a solução desidratante. Neste processo, a pressão é um fator importante uma vez que baixas pressões podem acelerar a difusão de água do alimento. $O$ objetivo do trabalho foi avaliar o efeito da pressão absoluta da DO sobre as propriedades mecânicas e morfológicas de melão amarelo utilizando como agente desidratante suco concentrado de uva (SU) e com fins de comparação solução de sacarose (SS).

\section{Resultados e Discussão}

Os melões (diâmetro $=11 \mathrm{~mm}$, altura $=10 \mathrm{~mm}$ ) foram desidratados $40^{\circ} \mathrm{C}$, por 1 hora. A proporção fruta: agente desidratante $\left(60^{\circ} \mathrm{Brix}\right)$ foi de $1: 10$. A variação na pressão não teve efeito significativo sobre os valores de tensão e deformação de Hencky, independente do agente desidratante; já, os parâmetros de módulo de Young e tenacidade apresentaram algumas diferenças significativas para SS e nenhuma diferença para SU (Tabelas 1 e 2). O melão desidratado com SU teve valores de tensão e deformação de Hencky, módulo de Young e tenacidade mais altos que o desidratado com SS.

A desidratação foi mais eficiente quando SU foi utilizado no processo, resultando em um produto com baixa $A_{W}(0,95-0,96)$, altos sólidos solúveis $\left(29-31^{\circ}\right.$ Brix) e baixa umidade (67-68,7\%) quando comparado com o melão desidratado com SS, independente da pressão. A perda de peso e a perda de agua do processo tiveram diferenças significativas com a variação da pressão e com o tipo de agente desidratante, sendo sempre maior quando utilizado o SU.

As microfotografias do tecido celular do melão antes e depois do processo de DO mostraram alterações significativas na estrutura do melão desidratado com SU (Figura 1D). Contudo, estas alterações não prejudicaram suas propriedades mecânicas como observado nas Tabelas 1 e 2.
Tabela 1. Valores normalizados ${ }^{*}$ das propriedades mecânicas ${ }^{* *}$ do melão desidratado.

\begin{tabular}{|c|c|c|c|c|}
\hline \multirow{2}{*}{$\begin{array}{c}\text { Pressão } \\
\text { (mbar) }\end{array}$} & \multicolumn{2}{|c|}{ Tensão de Hencky } & \multicolumn{2}{c|}{ Deformação de Hencky } \\
\cline { 2 - 5 } & $S S$ & $S U$ & $S S$ & $S U$ \\
\hline 200 & $0,83 \pm 0,16^{\mathrm{aB}}$ & $1,74 \pm 0,08^{\mathrm{aB}}$ & $1,74 \pm 0,04^{\mathrm{aB}}$ & $3,26 \pm 0,32^{\mathrm{aA}}$ \\
\hline $\mathbf{4 0 0}$ & $1,16 \pm 0,02^{\mathrm{aB}}$ & $2,06 \pm 0,12^{\mathrm{aA}}$ & $1,86 \pm 0,01^{\mathrm{aB}}$ & $4,19 \pm 0,07^{\mathrm{aA}}$ \\
\hline $\mathbf{6 0 0}$ & $1,23 \pm 0,08^{\mathrm{aA}}$ & $4,62 \pm 0,17^{\mathrm{aA}}$ & $1,83 \pm 0,1^{\mathrm{a}^{\mathrm{a}}}$ & $3,51 \pm 0,45^{\mathrm{aA}}$ \\
\hline $\begin{array}{c}\text { Pressão } \\
\text { (mbar) }\end{array}$ & \multicolumn{2}{|c|}{ Módulo de Young } & \multicolumn{2}{|c|}{ Tenacidade } \\
\cline { 2 - 5 } & $S S$ & $S U$ & $S S$ & $S U$ \\
\hline $\mathbf{2 0 0}$ & $0,41 \pm 0,00^{\mathrm{bB}}$ & $0,63 \pm 0,03^{\mathrm{aA}}$ & $1,25 \pm 0,16^{\mathrm{bB}}$ & $4,04 \pm 0,08^{\mathrm{aA}}$ \\
\hline $\mathbf{4 0 0}$ & $0,58 \pm 0,06^{\mathrm{abA}}$ & $0,5 \pm 0,01^{\mathrm{aA}}$ & $2,04 \pm 0,08^{\mathrm{aB}}$ & $6,66 \pm 0,55^{\mathrm{aA}}$ \\
\hline $\mathbf{6 0 0}$ & $0,66 \pm 0,07^{\mathrm{aA}}$ & $0,47 \pm 0,08^{\mathrm{aA}}$ & $2,00 \pm 0,15^{\mathrm{aA}}$ & $4,34 \pm 1,20^{\mathrm{aA}}$ \\
\hline
\end{tabular}

Letras minúsculas na mesma coluna e letras maiúsculas na mesma linha indicam diferenças significativas $(p<0,05)$. . . Razão entre os valores das amostras tratadas e seus equivalentes frescos. ${ }^{* *}$ Compressão uniaxial considerando $80 \%$ de deformação e velocidade de $1 \mathrm{~mm} / \mathrm{s}$.

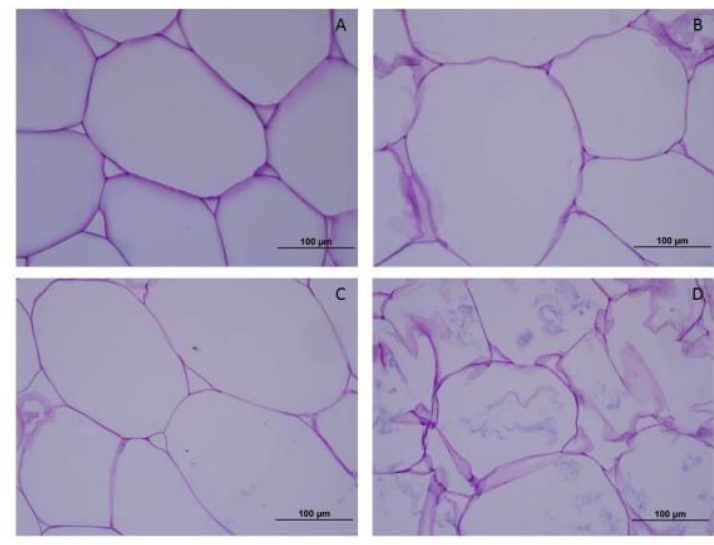

Figura 1. Microfotografias do tecido celular após desidratação na pressão de 200 mbar. Melão antes (A) e depois (B) da DO com SS, e antes (C) e depois (D) da DO com SU.

\section{Conclusões}

Uma alta redução da atividade de água (alvo principal da DO) e um produto mais firme podem ser obtidos com o emprego de suco concentrado de uva nas pressões avaliadas neste trabalho.

\section{Agradecimentos}

Os autores agradecem ao PIBIC-SAE pela bolsa de IC ao primeiro autor, e à CAPES pela bolsa de Pós-Doutorado ao terceiro autor. 